\title{
Larval swimming capacities affect genetic differentiation and range size in demersal marine fishes
}

\author{
Gerrit B. Nanninga*, Andrea Manica \\ Evolutionary Ecology Group, Department of Zoology, University of Cambridge, Cambridge, UK
}

\begin{abstract}
Dispersal is a fundamental process governing the ecological and evolutionary dynamics of any given species. Due to inherent challenges associated with measuring dispersal directly, identifying proxies for dispersal capacity has long been an active field of research across ecosystems. In marine systems, pelagic larval duration (PLD) has been one of the most widely used indicators of interspecific dispersal potential. The validity of this proxy, however, relies mostly on the assumption of entirely passive dispersal, a notion that has been challenged by findings of strong larval behavioural capabilities. Here, we assessed the effect of larval swimming capacities measured as mean critical swimming speed ( $U$-crit) on emergent species-level properties related to dispersal potential, population genetic structure and global range size, in demersal marine fishes. In a meta-analytic framework, we tested the relative importance of $U$-crit versus other intrinsic (PLD, egg type, adult body size) and extrinsic (genetic marker type, study scale) predictors of isolation-by-distance slope, global $F_{\mathrm{ST}}$ and range size. $U$-crit showed stronger relationships with all emergent response variables than PLD and was consistently the most important predictor in multi-model inference. Our findings indicate that larval swimming capacities could serve as a powerful indicator of a species' long-distance dispersal potential.
\end{abstract}

KEY WORDS: Larval dispersal · Critical swimming speed · Connectivity · Genetic structure - Isolationby-distance $\cdot$ Range size

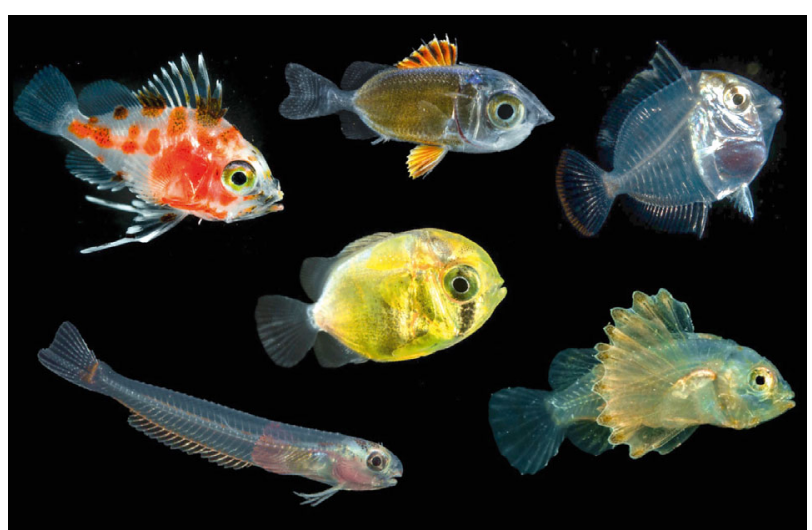

The swimming capacities of pelagic larvae affect gene flow and range size in demersal marine fishes.

Photo: Frank Baensch

\section{INTRODUCTION}

Dispersal has pervasive ecological and evolutionary consequences for the dynamics and persistence of any given species. In most marine organisms, dispersal is limited to a pelagic larval stage that links site-attached adult populations. Larval dispersal is the primary determinant of demographic connectivity, gene flow and range shifts in spatially segregated coastal populations, with important ramifications for population dynamics, species evolution and the resilience of populations to global change (Kritzer \& Sale 2004, Cowen \& Sponaugle 2009). At the same time, direct tracking of minute larvae in a vast and dy- 
namic ocean is notoriously challenging (Jones 2015), hampering a deeper understanding of the mechanisms regulating the spatiotemporal scales of larval dispersal.

Over the past decades, there has been substantial interest in identifying species-specific biological traits that could serve as proxies for interspecific variability in dispersal capacity (Kinlan et al. 2005, Lester et al. 2007, Shanks 2009, Weersing \& Toonen 2009, Selkoe \& Toonen 2011). One of the most commonly cited possible determinants of a species' dispersal potential is its pelagic larval duration (PLD), the length of time larvae spend in the water column after hatching and before settling into a benthic or demersal habitat (Selkoe \& Toonen 2011). PLD varies widely among and within marine taxa, and the simple notion is that the longer a larva spends in the water column, the higher its potential for dispersal by ocean currents (Scheltema 1971). This concept is based on the inherent assumption that larvae act as passive particles transported by a relatively uniform flow. However, extensive research over the past 2 decades has clearly demonstrated that the larvae of many marine organisms, including ascidians (Bingham \& Young 1991), bivalves (Shanks \& Brink 2005), corals (Dixson et al. 2014), decapod crustaceans (Radford et al. 2007) and gastropods (Poulin et al. 2002), exhibit strong behavioural preferences and are possibly able to influence their vertical and horizontal position in the water column. The larvae of coral reef fishes, in particular, have repeatedly been shown to be capable swimmers in terms of both speed (Fisher et al. 2005, Hogan et al. 2007) and endurance (Stobutzki \& Bellwood 1997), potentially enabling them to influence their dispersal trajectories relative to mean ocean currents (Paris \& Cowen 2004, Fisher 2005).

In theory, higher mobility should entail greater dispersal capacity (Clobert et al. 2012, Stevens et al. 2013). However, in the marine realm, larval navigation could be used in either direction: to increase dispersal distance by choosing and/or swimming with longshore currents, or to remain near the natal reef by selecting retentive flow features (e.g. eddies, fronts) and/or swimming against advective currents. To date, however, the directionality of active larval navigation as well as its relative importance versus passive drift remain largely unknown (but see Hogan \& Mora 2005).

Quantitative measures of mean dispersal distances are central to exploring the relationship between dispersal capacity and actual dispersal. One of the most frequently used approaches to estimate dispersal in marine systems is the use of neutral molecular markers, where allele frequencies of geographically scattered populations are used to infer levels of connectivity across multiple generations (Hellberg et al. 2002). This 'classical genetic' approach is based on the notion that, under certain assumptions, population differentiation should be inversely correlated with gene flow, allowing for the indirect inference of the spatial scale of larval dispersal (Wright 1943, Slatkin 1987). Marine ecosystems are known to exhibit extensive variation in spatial genetic structure among and within co-distributed taxa (Selkoe et al. 2008, 2014, Kelly \& Palumbi 2010) and there is great interest in determining the ecological factors driving these patterns (Selkoe et al. 2016).

Like genetic differentiation, geographic range size is an emergent species-level trait that is thought to be affected at least to some degree by dispersal capacity (Jablonski 2008, Riginos et al. 2014). Range edges are naturally dynamic and shifts in range occupancy are driven by different extrinsic (e.g. environmental stochasticity) and intrinsic (e.g. niche breath, environmental tolerance, dispersal ability) factors (Lester et al. 2007, Bates et al. 2014). There is often dramatic variability in the extent of the geographic area that even closely related marine species occupy (Brown et al. 1996) and considerable research effort has been invested in identifying the driving factors behind this variation (reviewed in Lester \& Ruttenberg 2005).

In recent decades, a considerable number of studies have tried to assess the potential effects of species-level dispersal capacity, measured as PLD, on genetic differentiation and range size across a range of taxa (reviewed in Selkoe \& Toonen 2011 and Lester et al. 2007, respectively). These studies have yielded equivocal results for both response variables, ranging from weak to very strong statistical relationships, indicating that PLD may not be the primary determinant of dispersal capacity in marine systems. More recently, other dispersal-related biological traits have hence been included in such tests, including spawning mode (Riginos et al. 2011, 2014) and adult body size (Luiz et al. 2013). Marine fishes are typically categorized according to their reproductive mode as either 'benthic brooders' (depositing eggs on the substrate) or 'pelagic spawners' (releasing floating eggs) (Cowen \& Sponaugle 2009). In general, pelagic spawners are believed to have higher dispersal potential than benthic brooders because (1) the egg phase already entails potential for advection, (2) PLDs are typically longer, and (3) greater reproductive output may increase the 
chance for long-distance dispersal events (Cowen \& Sponaugle 1997, Treml et al. 2012, Riginos et al. 2014). Adult body size has been associated with home range size (Kramer \& Chapman 1999), predation risk and tolerance to environmental variability (Munday \& Jones 1998), thereby potentially affecting dispersal capacity (Luiz et al. 2013). Lastly, larval behaviour has frequently been proposed as an important driver of dispersal capacity (Siegel et al. 2003, Shanks 2009, Selkoe \& Toonen 2011, Riginos et al. 2011). However, no study has yet quantitatively tested its effect on indirect measures of dispersal (but see Weersing \& Toonen [2009], who categorize taxon-specific swimming abilities as either 'weak' or 'strong').

The capacity of larvae to move relative to ocean currents has important ramifications for both dispersal (facilitated by vertical migration and sensory orientation) and survival (i.e. enhanced foraging and predator avoidance capabilities) (Leis 2007, Fiksen et al. 2007, Fisher \& Leis 2009). Swimming capabilities exhibited by fish larvae vary extensively among and within families, implying considerable variance in the extent to which larvae may be capable of affecting their own dispersal trajectories. The most widely used measures of swimming capabilities in fish larvae is critical swimming speed (U-crit), which involves challenging individuals at incrementally increasing swimming speeds until exhaustion (Plaut 2001). Here we used published estimates of $U$-crit to assess the relative importance of larval behaviour compared to other frequently tested biological traits (PLD, egg type and adult size) on population genetic estimates of dispersal and geographic range size in demersal marine fishes.

\section{MATERIALS AND METHODS}

\section{Focal species}

Our literature search was limited to demersal marine fishes with a relatively restricted adult home range $(<5 \mathrm{~km})$ and a PLD of at least $3 \mathrm{~d}$. The rational for these criteria was that (1) the majority of movements should be restricted to the larval phase and (2) swimming capacity can only begin to have any effect on dispersal after some minimum amount of time spent in the water column. In addition, we repeated analyses including the only direct developer for which all information was available, the damselfish Acanthochromis polyacanthus, to test the effect of data points with PLD $=0$.

\section{Swimming capacity estimates}

The majority of species-level mean $U$-crit estimates used in this analysis stem from 2 sources, Fisher et al. (2005) and Hogan et al. (2007), collectively representing 127 species (including 34 identified to genus level only) from 26 different families. Additional estimates of larval $U$-crit were obtained via a literature search in Web of Science ${ }^{\circledR}$ using the search terms 'marine', 'fish*', 'larva*', 'critical swimming speed' and 'u-crit'. The timing of $U$-crit measurements during larval development (e.g. pre- or post-flexion) may pose an important source of bias in a meta-analytic framework. Most measures used in this study were taken from individuals caught in light traps deployed near reef sites. It is thus likely that the majority of tested individuals were near the end of their pelagic stage (i.e. post-flexion).

\section{Genetic estimates of dispersal}

For each of the species with available larval $U$-crit estimates, we searched for published estimates of genetic population differentiation. We systematically searched for studies by using the search terms 'species $x^{\prime}$, 'isolation by distance', 'genetic structure', 'genetic population structure' and 'phylogeography'. For each genetic estimate of dispersal, the spatial scale of measurement of the study was also considered. If not directly provided, spatial scale was calculated as the maximum distance between sampling locations using details from the text and available maps (i.e. Google Earth).

The most commonly used metric for estimating dispersal based on genetic markers is Wright's fixation index ( $F_{\mathrm{ST}}$ and its derivatives), a measure of genetic variation between geographically separated sampling locations. At the most basic level, 'global $F_{\mathrm{ST}}$ ' presents a single estimate of the proportion of total genetic differentiation partitioned among subpopulations (Wright 1978). The spatial scale of sampling has a significant effect on estimates of global $F_{\mathrm{ST}}$ (Kinlan \& Gaines 2003, Bradbury et al. 2008, Selkoe \& Toonen 2011). Following Siegel et al. (2003) and Selkoe \& Toonen (2011), we therefore 'standardized' $F_{\mathrm{ST}}$ by dividing the reported value by the maximum pairwise geographic distance between sampling locations $\left(F_{\mathrm{ST}} \mathrm{km}^{-1}\right)$.

Another genetic estimate of dispersal distance is the slope of the 'isolation-by-distance' (IBD) relationship, which has been suggested to be a more robust correlate of dispersal scale than global $F_{\mathrm{ST}}$ (Selkoe \& 
Toonen 2011). Under a stepping stone model of dispersal, IBD predicts that 'pairwise $F_{\mathrm{ST}}$ ' (genetic divergence between any 2 sampled populations) will be positively correlated with geographic distance (Rousset 1997). If estimates of effective population size are available, the slope of the IBD function can be used to infer dispersal distances (Kinlan \& Gaines 2003, Pinsky et al. 2010). Here, IBD slopes were either extracted directly from reported values, or calculated from linearized pairwise $F_{\mathrm{ST}}\left[F_{\mathrm{ST}} /\left(1-F_{\mathrm{ST}}\right)\right]$ and geographic distance data, available from tables and maps, using Mantle tests with 10000 permutations in GenAlex v.6.503 (Peakall \& Smouse 2006) after setting negative $F_{\mathrm{ST}}$ values to zero. In some instances, when certain populations were strongly spatially isolated or separated from the rest of the study domain by a potential dispersal barrier, the IBD slope was estimated for a subset of the sampled populations (see Table S4 in the Supplement at www.int-res.com/ articles/suppl/m589p001_supp.pdf). Only slopes of statistically significant IBD relationships $(p<0.05)$ were retained.

In instances where 2 or more published estimates of either $F_{\mathrm{ST}}$ and/or IBD slope were found for 1 species, a single species datum was retained based on prioritizing the latest studies and/or the ones covering the greatest geographic extent. Prioritizing data in either direction had no effect on the overall results. In some instances, we used $U$-crit estimates of closely related species or the family mean (Table S4).

Variation in genetic marker types used across different studies has been shown to have a strong effect on meta-analyses of population genetic structure in marine fishes (Riginos et al. 2011, Selkoe \& Toonen 2011). We accounted for genetic marker type by categorising them according to mutation rates and mode of inheritance (biparental vs. maternal) into 4 groups: (1) mitochondrial DNA (mtDNA: cytochrome $\mathrm{b}$ and RFLPs), (2) mitochondrial control region (CR), (3) nuclear DNA (nDNA: AFLPs, RAPDs, ISSRs, allozymes), and (4) microsatellites (Msat). Overall results were robust to slightly different categorizations (data not shown).

\section{Other biological traits}

For most species, data on mean PLD estimates were obtained from the supplemental material in Luiz et al. (2013) or Stier et al. (2014) (for exceptions refer to Table S5 in our Supplement). The measure of range size used was the 'maximum linear distance $(\mathrm{km})$ within the spatial range of each species', which has been shown to be an adequate descriptor of a species' geographic extent (Lester \& Ruttenberg 2005, Mora et al. 2011). Data on range sizes were obtained either from the supplemental material in Luiz et al. (2013) or calculated using native range information from FishBase and Google Earth. Information on adult body size (maximum total length) and egg type (benthic or pelagic) was derived either from Luiz et al. (2013) or from FishBase. Although viviparous, we included the family Sebastidae in the benthic brooder category, as mouth brooders release fully developed larvae, rather than floating eggs.

\section{Statistical analyses}

To improve approximation to normality, all continuous variables were log-transformed prior to analysis. After testing for assumptions, we used univariate ordinary least squares models (OLS) in R (version 3.4.0) to examine the effects of mean species-level larval swimming capacities ( $U$-crit) and PLD on published estimates of $F_{\mathrm{ST}} \mathrm{km}^{-1}$, IBD slope and geographic range size. We then conducted model selection to determine the best set of predictors to explain genetic dispersal estimates and range size in multivariate linear models. To control for the nonindependence of shared traits among related species, we used linear mixed-effects models (LME), treating family and genus as nested random effects. Full models differed logically among the response variables (Table 1), but all included a subset and some interac-

Table 1. Full models used for selection of best models explaining dispersal potential in demersal marine fishes, measured as isolation-by-distance (IBD) slope, genetic variation between sampling locations $\left(F_{\mathrm{ST}} \mathrm{km}^{-1}\right)$ and geographic range size. $U$-crit: critical swimming speed; PLD: pelagic larval duration; 'marker type' refers to the studyspecific genetic marker, categorized according to mutation rates and mode of inheritance. See 'Materials and methods' for further explanation

\begin{tabular}{|c|c|}
\hline $\begin{array}{l}\text { Dependent } \\
\text { variable }\end{array}$ & Full model \\
\hline IBD slope & $\begin{array}{l}U \text {-crit + PLD + marker type + egg type + } \\
\text { study scale + adult size + U-crit:PLD + } \\
\text { egg type: } U \text {-crit + egg type:PLD + marker } \\
\text { type:study scale }\end{array}$ \\
\hline$F_{\mathrm{ST}} \mathrm{km}^{-1}$ & $\begin{array}{l}U \text {-crit }+ \text { PLD }+ \text { marker type + egg type + } \\
\text { adult size }+U \text {-crit:PLD + egg type: } U \text {-crit + } \\
\text { egg type:PLD }\end{array}$ \\
\hline $\begin{array}{l}\text { Range } \\
\text { size }\end{array}$ & $\begin{array}{l}U \text {-crit + PLD + egg type + adult size + } \\
U \text {-crit:PLD + egg type: } U \text {-crit + egg type:PLD }\end{array}$ \\
\hline
\end{tabular}


tion terms of the fixed variables $U$-crit $\left(\mathrm{cm} \mathrm{s}^{-1}\right)$, PLD (d), marker type (mtDNA, nDNA, CR, Msat), egg type (benthic, pelagic), study scale $(\mathrm{km})$ and mean maximum adult size $(\mathrm{cm})$. While the model for IBD slope included all mentioned predictors, the model for $F_{\mathrm{ST}} \mathrm{km}^{-1}$ excluded study scale (as it was implicit in the dependent variable) and the model for range size excluded both study scale and marker type (as they were both not applicable). We also ran an additional model on raw global $F_{\mathrm{ST}}$ including study scale as predictor. For all models, only interaction terms with an intuitive biological interpretation were included (Table 1). We ranked competing models using information-theoretic model selection in the MuMIn R package (Bartoń 2018) based on second-order Akaike information criterion (AICC) to account for small sample sizes. Models with $\triangle \mathrm{AICc}<2$ from the best model were considered as being substantially supported by the data and similar in their empirical support to the best model (Burnham \& Anderson 2003).

To assess the relative importance of each exploratory variable, we calculated the cumulative Akaike weight $(\omega)$ across all models in which the respective predictor occurred. Relative variable importance varies between 0 and 1, with larger values indicating higher importance compared to other exploratory variables.

We used $t$-tests to assess differences in predictor and response variables between pelagic spawners and benthic brooders.

\section{RESULTS}

\section{Dataset}

Our literature search yielded 23, 38 and 68 data points representing 13, 14 and 19 families for IBD slope, global $F_{\mathrm{ST}}$ and geographic range size, respectively. Whilst clearly more species-specific data points were available for either genetic estimates or dispersal traits, the availability of all estimates in a given species was a strong limiting factor. Values for IBD slope varied from $1.5 \times 10^{-6}$ to $7 \times 10^{-4}$ with a mean of $0.00014( \pm 0.00026 \mathrm{SD})$. Global $F_{\mathrm{ST}}$ estimates ranged from 0.001 to $0.713(0.095 \pm 0.16)$. The spatial scale of genetic studies ranged from 120 to $19000 \mathrm{~km} \mathrm{(4308}$ $\pm 5168 \mathrm{~km}$ ). Maximum geographic range size ranged from approximately 2500 to nearly $28000 \mathrm{~km}$ (11 $200 \pm$ $5334 \mathrm{~km}$ ). Values of $U$-crit ranged from 9.4 to $62.5 \mathrm{~cm}$ $\mathrm{s}^{-1}\left(35.4 \pm 13.2 \mathrm{~cm} \mathrm{~s}^{-1}\right)$, which is similar to the range of observed swimming speeds published so far (5.5 to $100 \mathrm{~cm} \mathrm{~s}^{-1}$, mean = 37.3; Fisher et al. 2005). Larval du- rations ranged from 10 to $90 \mathrm{~d}(30.8 \pm 16 \mathrm{~d})$. All raw data is available in Tables S4 \& S5 in the Supplement.

On average, pelagic spawners had significantly longer PLDs $\left(F_{1,66}=26.52, \mathrm{p}<0.001\right)$ and slightly higher $U$-crit values $\left(F_{1,66}=0.84, \mathrm{p}=0.364\right)$ than benthic brooders. Moreover, pelagic spawners exhibited marginally larger range sizes $\left(F_{1,66}=2.95, \mathrm{p}=0.091\right)$ and marginally lower mean $F_{\mathrm{ST}} \mathrm{km}^{-1}\left(F_{1,36}=3.80, \mathrm{p}=\right.$ $0.059)$ and IBD slopes $\left(F_{1,21}=3.01, \mathrm{p}=0.097\right)$.

\section{Simple linear models}

$U$-crit had markedly higher explanatory power than PLD in all of the 3 simple linear models (Fig. 1). All 3 relationships with $U$-crit were significant, explaining from nearly $20 \%\left(F_{\mathrm{ST}} \mathrm{km}^{-1}\right)$ to almost $40 \%$ (IBD slope) of variation in the genetic data and nearly $30 \%$ of variation in range size. In contrast, none of the relationships with PLD were significant and they all had very little explanatory power. When Acanthochromis polyacanthus (PLD =0) was included in the datasets, the relationships of PLD with both genetic estimates became significant (Fig. S1 in the Supplement).

When the relationships were broken down into the egg type or marker categories, trends remained the same within all categories for $U$-crit, but changed direction for some categories in the PLD models (Figs. S2 \& S3, Tables S1 \& S2 in the Supplement).

\section{Model selection}

For all 3 emergent response variables, $U$-crit was the predictor with the highest variable importance (IBD slope $=0.94, F_{\mathrm{ST}} \mathrm{km}^{-1}=0.97$, range size $=1$ ) (Fig. 2). For $F_{\mathrm{ST}} \mathrm{km}^{-1}$, genetic marker type had marginal importance (0.52), but negligible importance in the IBD slope models (0.13). (Note that marker type was not applicable for range size.) While PLD had importance values $>0.4$ for both genetic estimates, it was less important in predicting range size. All other predictor variables had minor importance for all response variables (Fig. 2).

Accordingly, $U$-crit occurred as a predictor in the top models for all response variables, as determined by AICc-based model selection (Table 2). In fact, the top models for both IBD slope and range size comprised $U$-crit as the single predictor, while the best model for $F_{\mathrm{ST}} \mathrm{km}^{-1}$ additionally included marker type. The second-best models for all response variables included PLD; however, values of $\omega$ rapidly decreased beyond the top model (Table S3 in the Supplement). 


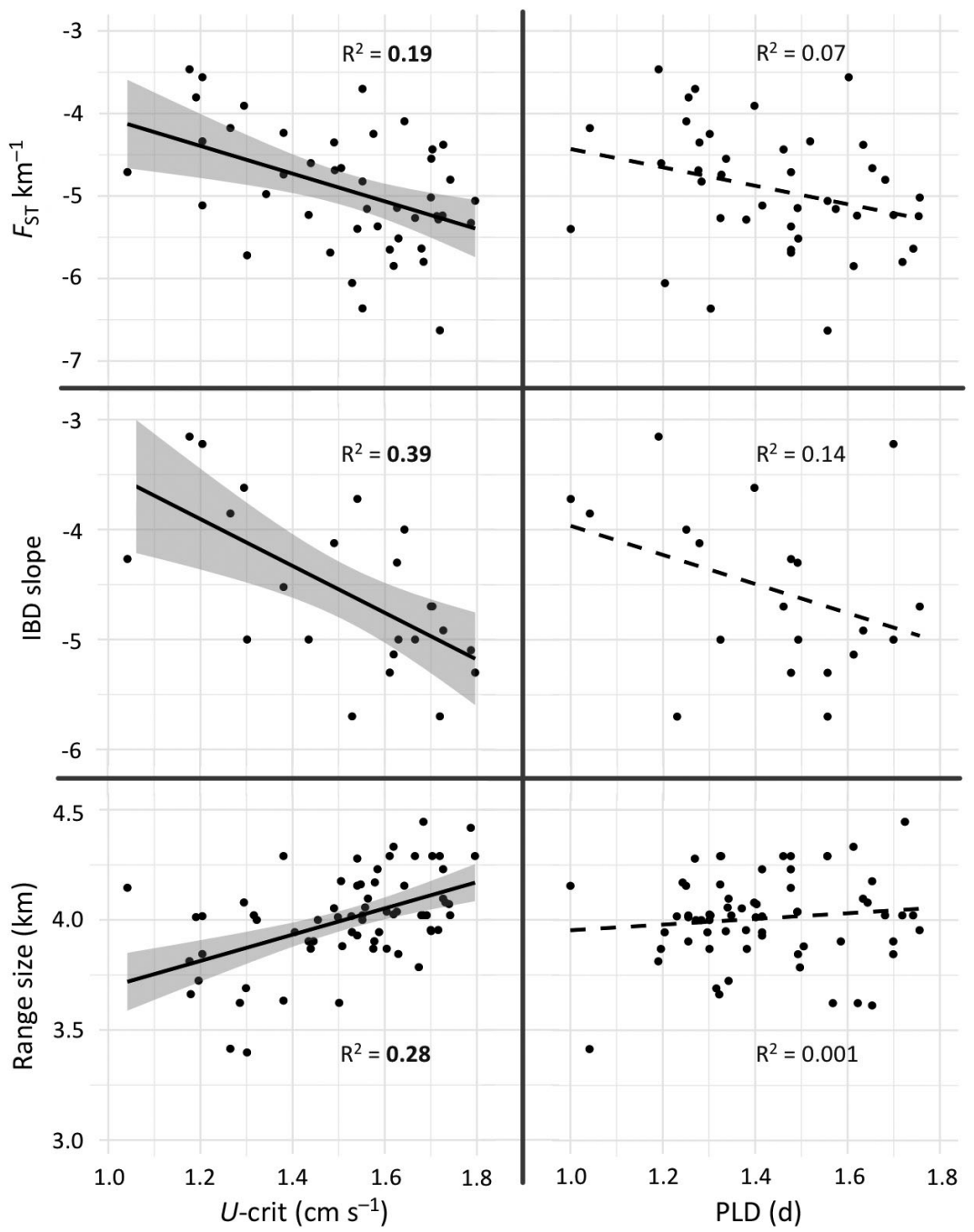

Fig. 1. Interactions of larval critical swimming speed ( $U$-crit, left panels) and pelagic larva duration (PLD, right panels) with isolation-by-distance (IBD) slope, genetic differentiation between sampling locations $\left(F_{\mathrm{ST}} \mathrm{km}^{-1}\right)$ and geographic range size in demersal marine fishes. Significant relationships are indicated by bold $\mathrm{R}^{2}$ values and solid regression lines (refer to Table $\mathrm{S} 1$ in the Supplement for exact p-values) and shaded areas represent $95 \%$ confidence intervals. All variables were log-transformed

Including a direct developer (i.e. $A$. polyacanthus) in the datasets did not change the overall results for any of the response variables. However, in the $F_{\mathrm{ST}} \mathrm{km}^{-1}$ models, the overall effect of marker type decreased (0.37). At the same time, PLD gained relative importance $(0.61)$, corresponding with the significant increase of model fit of PLD with $F_{\mathrm{ST}} \mathrm{km}^{-1}$ that was anchored in the single data point with PLD $=0$ (Fig. S1 in the Supplement).

\section{DISCUSSION}

Dispersal capacity has critical effects on a species' population dynamics, evolutionary stability, spatial distribution and resilience towards environmental change (Hanski \& Ovaskainen 2000, Lester \& Ruttenberg 2005, Riginos et al. 2014). Our meta-analysis indicates that larval critical swimming speed ( $U$-crit) is a powerful predictor of both genetic estimates of dispersal $\left(F_{\mathrm{ST}} \mathrm{km}^{-1}\right.$ and IBD slope) and geographic range size in demersal marine fishes (Figs. 1 \& 2, Table 2). In all our analyses, $U$-crit consistently showed stronger relationships with the dispersal-related response variables than other biological traits that are frequently cited as proxies of dispersal capacity in marine organisms (PLD, egg type and adult size) (Lester \& Ruttenberg 2005, Selkoe \& Toonen 2011, Luiz et al. 2013, Riginos et al. 2014), as well as study-specific factors that may affect estimates of genetic structure (marker type and study scale)

Table 2. Best models $(\triangle \mathrm{AICC}<2)$ explaining dispersal potential in demersal marine fishes, measured as IBD slope, $F_{\mathrm{ST}} \mathrm{km}^{-1}$ and range size determined by informationtheoretic model selection. See Table 1 legend for explanation of abbreviations

\begin{tabular}{|lcccc|}
\hline $\begin{array}{l}\text { Dependent } \\
\text { variable }\end{array}$ & Model & $\begin{array}{c}\text { AIC } \\
\text { weight }[\omega]\end{array}$ & df & $\begin{array}{c}\text { Marginal } \\
\mathrm{R}^{2}\end{array}$ \\
\hline IBD slope & $\begin{array}{c}U \text {-crit } \\
\text {-crit }+\end{array}$ & 0.25 & 5 & 0.36 \\
$F_{\text {ST km }} ~^{\text {Range size }}$ & $\begin{array}{c}\text { marker type } \\
\text {-crit }\end{array}$ & 0.55 & 8 & 0.43 \\
Rang & 5 & 0.3 \\
\hline
\end{tabular}

(Weersing \& Toonen 2009, Riginos et al. 2011). Overall, interspecific larval swimming speeds had strong positive effects on both gene flow and range size. Our findings indicate that, over evolutionary time scales, higher species-specific larval swimming abilities may increase long-distance dispersal capacity.

\section{Swimming speed as a correlate of dispersal}

While our findings thus corroborate the emergent paradigm of the importance of larval behaviour in shaping patterns of dispersal and gene flow in mar- 


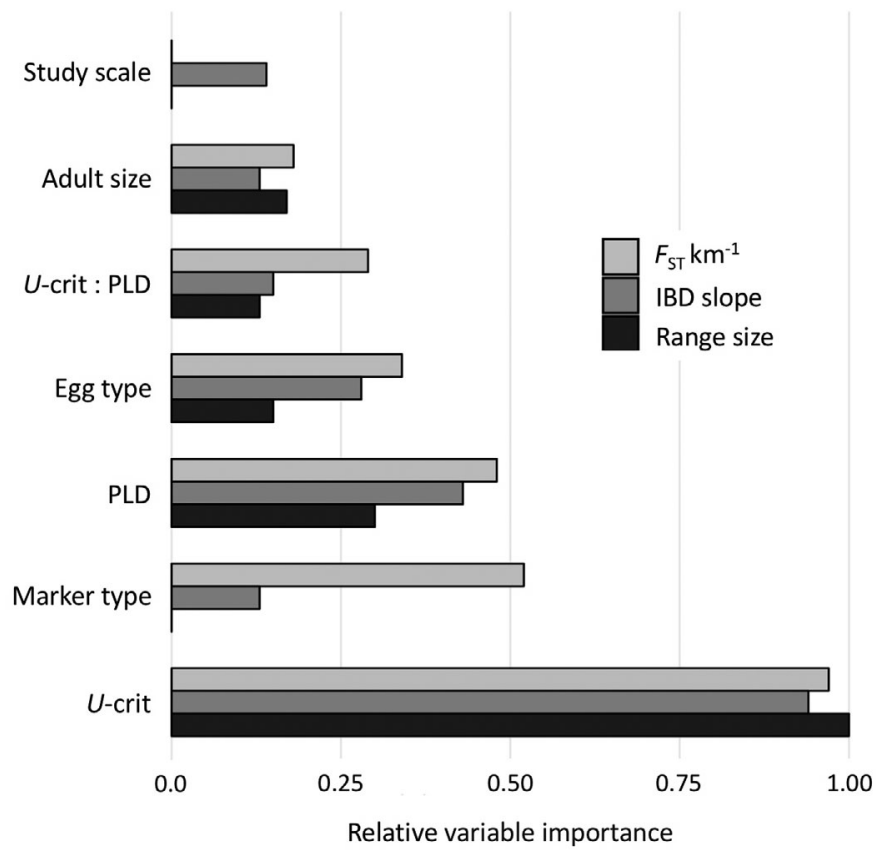

Fig. 2. Relative importance of the exploratory variables explaining dispersal potential in demersal marine fishes, measured as $F_{\mathrm{ST}} \mathrm{km}^{-1}$, IBD slope and range size, as determined by model selection. The only interaction term with importance values above 0.1 was $U$-crit:PLD. See Table 1 for a full list of model variables and explanation of abbreviations

ine fish populations (Kingsford et al. 2002, Leis 2006, 2007, Fiksen et al. 2007), they are somewhat contrary to expectations. In many situations, individual selection should favour philopatry in marine organisms (Almany et al. 2007, Burgess et al. 2016), not least because dispersal involves a substantial risk of being advected to unsuitable habitats. In accordance with this concept, biophysical models of larval dispersal have repeatedly shown that larvae may interact with oceanographic features in a way that minimizes advection from the natal site (Swearer et al. 1999, Paris \& Cowen 2004). The incorporation of larval behaviours, such as vertical migration, in mathematical simulations thus tends to reduce dispersal distances compared to passive drift models (Cowen et al. 2003, Paris et al. 2007). At the same time, there has been mounting empirical evidence of high levels of selfrecruitment (Jones et al. 2005, Berumen et al. 2012), exponentially declining dispersal kernels (Buston et al. 2012, Almany et al. 2013, D'Aloia et al. 2013) and behavioural preferences for natal reef cues (Gerlach et al. 2007) in different species of coral reef fishes. Both theory and empirical evidence hence seem to suggest that swimming capacities in marine fishes should mainly be used to facilitate local retention.
Our results and individual selection for philopatry are not mutually exclusive, however, because they reflect processes acting on different spatiotemporal scales. Dispersal in many marine fish populations is best described by fat-tailed dispersal kernels (Almany et al. 2013, D'Aloia et al. 2013), where a large proportion of settlement occurs near the natal site, but a few individuals disperse over long distances. If successful, these few long-distance dispersers may be sufficient to prevent the accumulation of any large population genetic differences (Slatkin 1987), or to expand a species' geographic range (Sakai et al. 2001). Strong swimming capacities in marine fish species may hence work at both ends of the ecological-evolutionary spectrum, to enable biophysical retention and to facilitate rare long-distance dispersal events.

Swimming performance typically develops linearly with body size during larval ontogeny, yet the slope of this relationship varies across species (Fisher 2005, Leis et al. 2007). The vast majority of estimates used in this study were taken from settlement-stage individuals, indicating that strong swimming capacities towards the end of the larval phase may be important for long-distance dispersers to reach suitable settlement habitat after travelling across stretches of open ocean. Rapid development of swimming capacities at earlier stages of development, on the other hand, may be more pertinent to the capacity for local retention. As yet, however, these theories remain purely speculative. An interesting approach to test these concepts would be to quantify the correlation between empirical levels of self-recruitment and interspecific swimming speeds (in addition to other biological traits). Unfortunately, at this point in time, insufficient data is available to assess this relationship.

In the context of global change, the development of swimming capacities during larval ontogeny gains further relevance. Changes in water temperature have been shown to simultaneously affect egg developmental rates (i.e. the duration of passive drift in pelagic spawners), larval growth (i.e. the development of swimming capacities) and larval duration (Pepin 1991, Green \& Fisher 2004). Increasing sea surface temperatures may thus have complex synergistic effects on individual-level dispersal capacities by reducing PLDs (thus theoretically decreasing dispersal capacity) while at the same time accelerating the development of swimming capacities (thus potentially increasing dispersal capacity).

If swimming capacity is related to long-distance dispersal, its effect should become more or less pronounced with longer and shorter larval durations, 
respectively. We found that the interaction term of $U$ crit and PLD had little importance in predicting any of the response variables (Fig. 2), potentially due to limitations in the dataset to properly identify such interactions. While PLDs in our study were representative of the typical range for demersal marine fishes (Luiz et al. 2013), only around $10 \%$ were $>50$ d, while more than half of the data points were between 20 and $40 \mathrm{~d}$. Our results may thus reflect patterns in the intermediate range of PLDs. Moreover, the potential for interactive effects of PLD and $U$-crit may plateau at long PLDs, because physical forces may become more important relative to behaviour. Similarly, even the highest swimming capacities will have little effect on dispersal for species with very short PLDs.

\section{Alternative measures of swimming speed}

$U$-crit is a measure of maximum aerobic swimming speed maintainable over short periods, presenting an important ability of larval fishes to facilitate short term vertical and horizontal movements, foraging and escaping predation (Fisher 2005). High levels of $U$-crit may thus correlate with dispersal distance because they are directly related to larval survival, rather than facilitating active long-distance movements. In this context, other measures of swimming capacity, such as 'routine swimming speed', may be more appropriate (Peck et al. 2012). Mean levels of larval $U$-crit, however, have been shown to strongly correlate with other measures of swimming performance, including 'routine swimming activity' (Fisher \& Bellwood 2003), 'sustained swimming' (Fisher \& Wilson 2004) and 'in situ swimming speeds' (Leis \& Fisher 2006). $U$-crit should hence present a valuable proxy for ecologically important swimming capabilities of pre-settlement fish larvae (Fisher 2005, Fisher \& Leis 2009).

\section{Pelagic larval duration}

Dispersal is an emergent property, determined by multiple traits with different functions (Burgess et al. 2016) and, undoubtedly, there are a multitude of potential intrinsic (e.g. life-history, niche breadth, environmental tolerance, fecundity) and extrinsic (e.g. oceanography, habitat configuration, biogeographic barriers) factors affecting interspecific variation in realized dispersal potential (Lester et al. 2007, Cowen \& Sponaugle 2009, Mora et al. 2011, Selkoe et al. 2016). Probably due to the appeal of its conceptual simplicity and/or a lack of suitable alternative measures, PLD has been invoked as the primary specieslevel determinant of dispersal potential in marine organisms (including fishes) for several decades (Thresher \& Brothers 1985, Riginos \& Victor 2001, Lester \& Ruttenberg 2005, Bradbury et al. 2008, Weersing \& Toonen 2009). In our meta-analysis, we found that PLD had relatively weak negative relationships with genetic estimates of dispersal and effectively no relationship with range size (Fig. 1).

These findings concur with previous multispecies comparisons of PLD with genetic structure in marine fishes (Bay et al. 2006, Bradbury et al. 2008, Riginos et al. 2011). Significant relationships of PLD with genetic dispersal estimates reported in some studies are typically anchored by species that lack a pelagic larval phase (Doherty et al. 1995, Bay et al. 2006, Weersing \& Toonen 2009). In our analyses, we also found that the inclusion of a direct developer, Acanthochromis polyacanthus, significantly enhanced the relationship of PLD with genetic estimates. However, data points with PLD $=0$ may add limited informative value to the relationship because such species inherently lack extensive larval dispersal potential.

The strength of the relationship of PLD with species range size, on the other hand, has been shown to be highly dependent on the ocean basin within which the relationship was assessed (Kinlan et al. 2005, Lester et al. 2007), probably due to physical constraints on range size within regions (Luiz et al. 2013). In our study, we lacked a sufficient sample size to assess the relationship at an ocean basin scale; however, our results concur with previous studies demonstrating a weak relationship of PLD with range size at a global scale in marine fishes (Victor \& Wellington 2000, Lester \& Ruttenberg 2005, Lester et al. 2007, Mora et al. 2011, Luiz et al. 2013).

There have been numerous excellent discussions on the issues related to using PLD as a predictor of dispersal potential in marine organisms, including large intraspecific variability of PLDs, unreliable measures of PLDs, differences in study-specific sampling designs, or evolutionary history (Helfman et al. 2009, Weersing \& Toonen 2009, Mora et al. 2011, Selkoe \& Toonen 2011).

\section{Egg type and adult size}

Two further biological traits that have frequently been cited as proxies for dispersal capacity, egg type and maximum adult body size, also had limited importance when predicting both genetic structure 
and range size, compared to $U$-crit. Our findings seem to contradict previous studies that have demonstrated significant effects of both egg type and adult size on genetic structure (Bradbury et al. 2008, Riginos et al. 2011, 2014) and range size (Lester et al. 2007, Luiz et al. 2013) in marine fishes. However, our results have to be viewed in relation to the dominant effect of swimming speed on the analyses. When model selection was run without including $U$-crit as a predictor, egg type became the most important factor in explaining both $F_{\mathrm{ST}} \mathrm{km}^{-1}$ and range size, albeit still with only marginal and negligible importance, respectively (Fig. S4 in the Supplement).

Moreover, our findings concur with the general expectation that pelagic eggs should entail higher dispersal capacity (Treml et al. 2012). On average, we observed higher levels of gene flow and larger range sizes, albeit non-significant, in pelagic spawners, while at the same time, we found that pelagic spawners had longer mean PLDs and faster mean swimming speeds. The latter trend is confirmed in more extensive datasets of larval $U$-crit (e.g. Fisher et al. 2005).

Considering the importance of larval behaviour identified here, the finding of stronger relationships of PLD with IBD slope and range size among benthic brooding species compared to pelagic spawners (Table S1 in the Supplement) was somewhat unexpected. While larvae hatching from benthic eggs possess at least some degree of motility right from the start (Leis et al. 2007), pelagic eggs drift entirely passively for up to several days. Since the concept of the relationship of PLD with dispersal potential is based on a notion of passive drift, we would thus have expected stronger correlations within the pelagic category, if any. One possible explanation is that egg type may have a more pronounced effect on levels of local retention than on rates of evolutionary connectivity. Even a few days as an entirely passive particle may be sufficient to drastically diminish any chances of returning to the natal reef after hatching. This explanation is supported by recent findings of significantly lower rates of self-recruitment and longer dispersal distances in a pelagic spawning species, Chaetodon vagabundus, compared to a benthic brooder, Amphiprion percula, within the same reefscape (Almany et al. 2017). Interestingly, larvae of the family Chaetodontidae typically have higher swimming capacities than those of Amphiprioninae, indicating that, at least in this case, swimming capacities may either not be used to enhance local retention as indicated above, or that they are insufficient to compensate for passive advection occurring during the egg stage.

\section{Marker type and study scale}

The type of genetic marker used in each study had different relative importance depending on the genetic response variable. Marker type was of negligible importance in predicting IBD slope, but had a stronger effect in the models for $F_{\mathrm{ST}} \mathrm{km}^{-1}$ (Fig. 2). Global $F_{\text {ST }}$ and IBD are subject to different assumptions. Under an island model of dispersal, global $F_{\mathrm{ST}}$ is predicted to decrease with increasing rates of migration when effective population sizes are uniform (Hellberg et al. 2002). Because we are testing proxies for dispersal scale, one important assumption is that migration is coupled to dispersal distance (Selkoe \& Toonen 2011). Another assumption is the approximation of a drift-migration equilibrium among the sampled populations (Hutchison \& Templeton 1999). The number of generations it takes to reach this equilibrium depends on effective population size and migration rates, but also on the mutation rate of the markers under consideration (Selkoe \& Toonen 2011). In situations where a statistically significant IBD pattern is detected, it is more likely that these basic assumptions have been met, or at least approached (Hutchison \& Templeton 1999, Selkoe \& Toonen 2011).

Despite the higher robustness towards variability in marker type, both dispersal proxies, $U$-crit and PLD, also explained significantly higher portions of variability in IBD slope than in $F_{\mathrm{ST}} \mathrm{km}^{-1}$ ( $U$-crit: 39 vs. $19 \%$, PLD: 14 vs. $7 \%$, respectively). Overall, our findings hence substantiate the suggestion of Selkoe \& Toonen (2011) that IBD slope may be a more robust correlate of dispersal scale than global $F_{\mathrm{ST}}$.

\section{CONCLUSIONS}

Our findings indicate that larval swimming capacities may be a powerful proxy for evolutionary connectivity and geographic range size in demersal marine fishes. Considering the potential utility of swimming speeds in predicting interspecific dispersal capacity, we advocate the collection of further empirical estimates of larval $U$-crit (and other measures of swimming capacity, such as routine speeds and endurance) across a broad range of marine taxa to enhance our understanding of the relative importance of larval behaviour versus other intrinsic and extrinsic factors. At the same time, rising numbers of published empirical estimates of dispersal promise the potential for interesting meta-analyses directly assessing the effect of larval behaviour on patters of demographic connectivity. 
Despite its key role in marine ecology and evolution, larval dispersal remains an enigmatic process. Our findings corroborate the notion of larval behaviour as a key driver of dispersal pathways and highlight the need to incorporate interspecific swimming capacities into mathematical models of demographic connectivity and gene flow.

Acknowledgements. This study was funded by a research fellowship awarded to G.B.N. by the German Research Foundation (DFG), grant number NA 1250/1-1. We thank Pablo Saenz-Agudelo and 4 anonymous reviewers for helpful comments on early drafts of the manuscript.

\section{LITERATURE CITED}

Almany GR, Berumen ML, Thorrold SR, Planes S, Jones GP (2007) Local replenishment of coral reef fish populations in a marine reserve. Science 316:742-744

Almany GR, Hamilton RJ, Bode M, Matawai M and others (2013) Dispersal of grouper larvae drives local resource sharing in a coral reef fishery. Curr Biol 23:626-630

Almany GR, Planes S, Thorrold SR, Berumen ML and others (2017) Larval fish dispersal in a coral-reef seascape. Nat Ecol Evol 1:148-154

Bartoń K (2018) Package 'MuMIn'. R package version 1.40.4. ftp://155.232.191.229/cran/web/packages/MuMIn/ MuMIn.pdf

Bates AE, Pecl GT, Frusher S, Hobday AJ and others (2014) Defining and observing stages of climate-mediated range shifts in marine systems. Glob Environ Change 26: 27-38

Bay LK, Crozier RH, Caley MJ (2006) The relationship between population genetic structure and pelagic larval duration in coral reef fishes on the Great Barrier Reef. Mar Biol 149:1247-1256

*Berumen ML, Almany GR, Planes S, Jones GP, SaenzAgudelo P, Thorrold SR (2012) Persistence of self-recruitment and patterns of larval connectivity in a marine protected area network. Ecol Evol 2:444-452

Bingham BL, Young CM (1991) Larval behavior of the ascidian Ecteinascidia turbinata Herdman; an in situ experimental study of the effects of swimming on dispersal. J Exp Mar Biol Ecol 145:189-204

Bradbury IR, Laurel B, Snelgrove PVR, Bentzen P, Campana SE (2008) Global patterns in marine dispersal estimates: the influence of geography, taxonomic category and life history. Proc R Soc B 275:1803-1809

Brown JH, Stevens GC, Kaufman DM (1996) The geographic range: size, shape, boundaries, and internal structure. Annu Rev Ecol Syst 27:597-623

* Burgess SC, Baskett ML, Grosberg RK, Morgan SG, Strathmann RR (2016) When is dispersal for dispersal? Unifying marine and terrestrial perspectives. Biol Rev Camb Philos Soc 91:867-882

Burnham KP, Anderson DR (2003) Model selection and multimodel inference: a practical information-theoretic approach. Springer, New York, NY

Buston PM, Jones GP, Planes S, Thorrold SR (2012) Probability of successful larval dispersal declines fivefold over $1 \mathrm{~km}$ in a coral reef fish. Proc R Soc B 279:1883-1888

Clobert J, Baguette M, Benton TG, Bullock JM (2012) Dis- persal ecology and evolution. Oxford University Press, Oxford

Cowen RK, Sponaugle S (1997) Relationships between early life history traits and recruitment among coral reef fishes. In: Chambers RC, Tripple E (eds) Early life history and recruitment in fish populations. Springer, New York, NY, p 423-449

Cowen RK, Sponaugle S (2009) Larval dispersal and marine population connectivity. Annu Rev Mar Sci 1:443-466

Cowen RK, Paris CB, Olson DB, Fortuna JL (2003) The role of long distance dispersal versus local retention in replenishing marine populations. Gulf Caribb Res 14: 129-138

D'Aloia CC, Bogdanowicz SM, Majoris JE, Harrison RG, Buston PM (2013) Self-recruitment in a Caribbean reef fish: a method for approximating dispersal kernels accounting for seascape. Mol Ecol 22:2563-2572

* Dixson DL, Abrego D, Hay ME (2014) Chemically mediated behavior of recruiting corals and fishes: a tipping point that may limit reef recovery. Science 345:892-897

* Doherty PJ, Planes S, Mather P (1995) Gene flow and larval duration in seven species of fish from the Great Barrier Reef. Ecology 76:2373-2391

Fiksen $\varnothing$, Jørgensen C, Kristiansen T, Vikebø F, Huse G (2007) Linking behavioural ecology and oceanography: larval behaviour determines growth, mortality and dispersal. Mar Ecol Prog Ser 347:195-205

Fisher R (2005) Swimming speeds of larval coral reef fishes: impacts on self-recruitment and dispersal. Mar Ecol Prog Ser 285:223-232

Fisher R, Bellwood DR (2003) Undisturbed swimming behaviour and nocturnal activity of coral reef fish larvae. Mar Ecol Prog Ser 263:177-188

Fisher R, Leis J (2009) Swimming performance in larval fishes: from escaping predators to the potential for long distance migration. In: Domenici P, Kapoor BG (eds) Fish locomotion: an eco-ethological perspective. CRC Press, Boca Raton, FL, p 333-373

Fisher R, Wilson SK (2004) Maximum sustainable swimming speeds of late-stage larvae of nine species of reef fishes. J Exp Mar Biol Ecol 312:171-186

Fisher R, Leis JM, Clark DL, Wilson SK (2005) Critical swimming speeds of late-stage coral reef fish larvae: variation within species, among species and between locations. Mar Biol 147:1201-1212

Kerlach G, Atema J, Kingsford MJ, Black KP, Miller-Sims V (2007) Smelling home can prevent dispersal of reef fish larvae. Proc Natl Acad Sci USA 104:858-863

Green BS, Fisher R (2004) Temperature influences swimming speed, growth and larval duration in coral reef fish larvae. J Exp Mar Biol Ecol 299:115-132

Hanski I, Ovaskainen O (2000) The metapopulation capacity of a fragmented landscape. Nature 404:755-758

Helfman G, Collette BB, Facey DE, Bowen BW (2009) The diversity of fishes: biology, evolution, and ecology. WileyBlackwell, Chichester

Hellberg ME, Burton RS, Neigel JE, Palumbi SR (2002) Genetic assessment of connectivity among marine populations. Bull Mar Sci 70:273-290

Hogan JD, Mora C (2005) Experimental analysis of the contribution of swimming and drifting to the displacement of reef fish larvae. Mar Biol 147:1213-1220

Hogan JD, Fisher R, Nolan C (2007) Critical swimming speed of settlement-stage coral reef fishes from the Caribbean: a methodological and geographical comparison. 
Bull Mar Sci 80:219-231

Hutchison DW, Templeton AR (1999) Correlation of pairwise genetic and geographic distance measures: inferring the relative influences of gene flow and drift on the distribution of genetic variability. Evolution 53:1898-1914

Jablonski D (2008) Species selection: theory and data. Annu Rev Ecol Evol Syst 39:501-524

Jones GP (2015) Mission impossible: unlocking the secrets of coral reef fish dispersal. In: Mora C (ed) Ecology of fishes on coral reefs. Cambridge University Press, Cambridge, p 16-28

Jones GP, Planes S, Thorrold SR (2005) Coral reef fish larvae settle close to home. Curr Biol 15:1314-1318

Kelly RP, Palumbi SR (2010) Genetic structure among 50 species of the northeastern Pacific rocky intertidal community. PLOS ONE 5:e8594

Kingsford MJ, Leis JM, Shanks A, Lindeman KC, Morgan SG, Pineda J (2002) Sensory environments, larval abilities and local self-recruitment. Bull Mar Sci 70:309-340

Kinlan BP, Gaines SD (2003) Propagule dispersal in marine and terrestrial environments: a community perspective. Ecology 84:2007-2020

Kinlan BP, Gaines SD, Lester SE (2005) Propagule dispersal and the scales of marine community process. Divers Distrib 11:139-148

Kramer DL, Chapman MR (1999) Implications of fish home range size and relocation for marine reserve function. Environ Biol Fishes 55:65-79

Kritzer JP, Sale PF (2004) Metapopulation ecology in the sea: from Levins' model to marine ecology and fisheries science. Fish Fish 5:131-140

Leis JM (2006) Are larvae of demersal fishes plankton or nekton? Adv Mar Biol 51:57-141

Leis JM (2007) Behaviour as input for modelling dispersal of fish larvae: behaviour, biogeography, hydrodynamics, ontogeny, physiology and phylogeny meet hydrography. Mar Ecol Prog Ser 347:185-193

Leis JM, Fisher R (2006) Swimming speed of settlementstage reef-fish larvae measured in the laboratory and in the field: a comparison of critical speed and in situ speed. In: Suzuki Y (ed) Proc 10th Int Coral Reef Symp, p 438-445

Leis JM, Hay AC, Lockett MM, Chen JP, Fang LS (2007) Ontogeny of swimming speed in larvae of pelagicspawning, tropical, marine fishes. Mar Ecol Prog Ser 349: 255-267

* Lester SE, Ruttenberg BI (2005) The relationship between pelagic larval duration and range size in tropical reef fishes: a synthetic analysis. Proc R Soc B 272:585-591

Lester SE, Ruttenberg BI, Gaines SD, Kinlan BP (2007) The relationship between dispersal ability and geographic range size. Ecol Lett 10:745-758

Luiz OJ, Allen AP, Robertson DR, Floeter SR and others (2013) Adult and larval traits as determinants of geographic range size among tropical reef fishes. Proc Natl Acad Sci USA 110:16498-16502

Mora C, Treml EA, Roberts J, Crosby K, Roy D, Tittensor DP (2011) High connectivity among habitats precludes the relationship between dispersal and range size in tropical reef fishes. Ecography 35:89-96

Munday PL, Jones GP (1998) The ecological implications of small body size among coral-reef fishes. Oceanogr Mar Biol Annu Rev 36:373-411

Paris CB, Cowen RK (2004) Direct evidence of a biophysical retention mechanism for coral reef fish larvae. Limnol
Oceanogr 49:1964-1979

* Paris CB, Chérubin LM, Cowen RK (2007) Surfing, spinning, or diving from reef to reef: effects on population connectivity. Mar Ecol Prog Ser 347:285-300

Peakall ROD, Smouse PE (2006) GENALEX 6: genetic analysis in Excel. Population genetic software for teaching and research. Mol Ecol Notes 6:288-295

Peck MA, Huebert KB, Llopiz JK (2012) Intrinsic and extrinsic factors driving match-mismatch dynamics during the early life history of marine fishes. Adv Ecol Res 47: 177-302

Pepin P (1991) Effect of temperature and size on development, mortality, and survival rates of the pelagic early life history stages of marine fish. Can J Fish Aquat Sci 48: 503-518

Pinsky ML, Montes HR Jr, Palumbi SR (2010) Using isolation by distance and effective density to estimate dispersal scales in anemonefish. Evolution 64:2688-2700

*Plaut I (2001) Critical swimming speed: its ecological relevance. Comp Biochem Physiol A Mol Integr Physiol 131: 41-50

* Poulin E, Palma AT, Leiva G, Narvaez D, Pacheco R, Navarrete SA, Castilla JC (2002) Avoiding offshore transport of competent larvae during upwelling events: the case of the gastropod Concholepas concholepas in Central Chile. Limnol Oceanogr 47:1248-1255

Radford CA, Jeffs AG, Montgomery JC (2007) Directional swimming behavior by five species of crab postlarvae in response to reef sound. Bull Mar Sci 80:369-378

* Riginos C, Victor BC (2001) Larval spatial distributions and other early life-history characteristics predict genetic differentiation in eastern Pacific blennioid fishes. Proc R Soc B 268:1931-1936

* Riginos C, Douglas KE, Jin Y, Shanahan DF, Treml EA (2011) Effects of geography and life history traits on genetic differentiation in benthic marine fishes. Ecography 34:566-575

Riginos C, Buckley YM, Blomberg SP, Treml EA (2014) Dispersal capacity predicts both population genetic structure and species richness in reef fishes. Am Nat 184: $52-64$

Rousset F (1997) Genetic differentiation and estimation of gene flow from F-statistics under isolation by distance. Genetics 145:1219-1228

* Sakai AK, Allendorf FW, Holt JS, Lodge DM and others (2001) The population biology of invasive species. Annu Rev Ecol Syst 32:305-332

* Scheltema RS (1971) Larval dispersal as a means of genetic exchange between geographically separated populations of shallow-water benthic marine gastropods. Biol Bull 140:284-322

* Selkoe KA, Toonen RJ (2011) Marine connectivity: a new look at pelagic larval duration and genetic metrics of dispersal. Mar Ecol Prog Ser 436:291-305

* Selkoe KA, Henzler CM, Gaines SD (2008) Seascape genetics and the spatial ecology of marine populations. Fish Fish 9:363-377

* Selkoe KA, Gaggiotti OE, Bowen BW, Toonen RJ (2014) Emergent patterns of population genetic structure for a coral reef community. Mol Ecol 23:3064-3079

* Selkoe KA, Aloia CCD, Crandall ED, Iacchei M and others (2016) A decade of seascape genetics: contributions to basic and applied marine connectivity. Mar Ecol Prog Ser 554:1-19

* Shanks AL (2009) Pelagic larval duration and dispersal 
distance revisited. Biol Bull 216:373-385

Shanks AL, Brink L (2005) Upwelling, downwelling, and cross-shelf transport of bivalve larvae: test of a hypothesis. Mar Ecol Prog Ser 302:1-12

Siegel DA, Kinlan BP, Gaylord B, Gaines SD (2003) Lagrangian descriptions of marine larval dispersion. Mar Ecol Prog Ser 260:83-96

Slatkin M (1987) Gene flow and the geographic structure of natural populations. Science 236:787-792

Stevens VM, Trochet A, Blanchet S, Moulherat S, Clobert J, Baguette $M$ (2013) Dispersal syndromes and the use of life-histories to predict dispersal. Evol Appl 6:630-642

Stier AC, Hein AM, Parravicini V, Kulbicki M (2014) Larval dispersal drives trophic structure across Pacific coral reefs. Nat Commun 5:5575-5578

Stobutzki IC, Bellwood DR (1997) Sustained swimming abilities of the late pelagic stages of coral reef fishes. Mar Ecol Prog Ser 149:35-41

Swearer SE, Caselle JE, Lea DW, Warner RR (1999) Larval

Editorial responsibility: Myron Peck,

Hamburg, Germany retention and recruitment in an island population of a coral-reef fish. Nature 402:799-802

* Thresher RE, Brothers EB (1985) Reproductive ecology and biogeography of Indo-West Pacific angelfishes (Pisces: Pomacanthidae). Evolution 39:878-887

*Treml EA, Roberts JJ, Chao Y, Halpin PN, Possingham HP, Riginos C (2012) Reproductive output and duration of the pelagic larval stage determine seascape-wide connectivity of marine populations. Integr Comp Biol 52:525-537

* Victor B, Wellington G (2000) Endemism and the pelagic larval duration of reef fishes in the eastern Pacific Ocean. Mar Ecol Prog Ser 205:241-248

*Weersing K, Toonen RJ (2009) Population genetics, larval dispersal, and connectivity in marine systems. Mar Ecol Prog Ser 393:1-12

Wright S (1943) Isolation by distance. Genetics 28:114-138

Wright S (1978) Evolution and the genetics of populations, Vol 4. Variability within and among natural populations. University of Chicago Press, Chicago, IL

Submitted: October 19, 2017; Accepted: February 2, 2018

Proofs received from author(s): February 19, 2018 